\title{
A teoria do jogo de Elkonin e a educação infantil
}

\author{
Suzana Marcolino \\ Universidade Estadual Paulista "Julio de Mesquita Filho" Marília, SP \\ Flávia Cristina Oliveira Murbach de Barros \\ Universidade Estadual Paulista "Julio de Mesquita Filho" Marilia, SP \\ Suely Amaral Mello \\ Universidade Estadual Paulista "Julio de Mesquita Filho", Marília, SP
}

\begin{abstract}
Resumo
O artigo é um estudo bibliográfico que analisa as teses centrais da Teoria Histórico-Cultural do Jogo desenvolvida por D.B. Elkonin e colaboradores. O objetivo é identificar elementos que possam subsidiar a organização da educação na infância tendo o jogo como atividade-guia. As teses configuram uma sólida teoria sobre o jogo infantil, apresentando como elementos originais a concepção histórica do surgimento do jogo e seu caráter social na ontogenia. Conclui-se que, para a Teoria Histórico-Cultural do Jogo, o eixo de uma educação na infância que leve em conta o jogo como atividade-guia deve incidir sobre a apresentação das várias esferas da vida social e do conteúdo das atividades humanas. Entendese que o objetivo da intervenção pedagógica no jogo protagonizado é o desenvolvimento do papel social representado. Discute-se que o jogo protagonizado não deve se opor a outras atividades, tampouco deve ser considerado como atividade a preponderar sobre as demais.
\end{abstract}

Palavras-chave: Jogos, educação infantil, D. B. Elkonin.

\section{Elkonin's play theory and early childhood education}

\begin{abstract}
This paper analyzes the Psychology of Play developed by D. Elkonin and his followers through examining the central theses of the culturalhistorical theory. The goal is to identify elements that can support the organization of early childhood education practices. The cultural-historical theses represent a solid theory about children's play, featuring an original contribution to understand the historical emergence of play and its social nature in ontogeny. Based on Cultural-historical theory of play, we conclude that early childhood education which considers play as the leading activity must relate to the experience of various spheres of social life and the content of human activities. It is understood that the goal of educational intervention in children play is the development of the social role represented in the game. It is argued that play should neither oppose nor prevail over other activities.
\end{abstract}

Keywords: Games, early childhood education, D. B. Elkonin.

\section{La teoría del juego de Elkonin y la educación infantil}

\section{Resumen}

El artículo es un estudio bibliográfico que analiza las tesis centrales de la Teoría Histórico-Cultural del Juego desarrollada por D.B. Elkonin y colaboradores. El objetivo es identificar elementos que puedan subsidiar la organización de la educación en la infancia teniendo el juego como actividad-guía. Las tesis constituyen una sólida teoría sobre el juego infantil y presentan como elementos originales la concepción histórica de aparición del juego y su carácter social en la ontogenia. Se concluye que para la Teoría Histórico-Cultural del Juego el eje de una educación inicial en la infancia que tiene en cuenta el juego como actividad-guía debe incidir sobre la presentación de varias esferas de la vida social y del contenido de las actividades humanas. Se entiende que el objetivo de la intervención pedagógica en el juego protagonizado es el desarrollo del papel social representado. Se argumenta que el juego protagonizado no debe oponerse a otras actividades y tampoco debe ser considerado como actividad a preponderar sobre las demás.

Palabras Clave: Juegos, crianza del niño, D. B. Elkonin. 


\section{Introdução}

Este artigo analisa as teses centrais da Teoria Histórico-Cultural do Jogo que emergem das pesquisas de Elkonin e seus colaboradores. Em seu conjunto, as teses configuram uma sólida teoria sobre o jogo infantil, capaz de subsidiar a educação na infância, levando em conta o jogo como atividade-guia da criança pré-escolar.

Como indica Lazaretti (2011), Elkonin parte das teses vigotskianas sobre a brincadeira infantil e assume o enfoque histórico-cultural no estudo do desenvolvimento da criança. Propõe a periodização do desenvolvimento, caracterizada em cada fase por uma atividade-guia por meio da qual se organiza a relação entre o indivíduo e o mundo social (Facci, 2004), sendo o jogo de papéis a atividade-guia da idade pré-escolar.

Lazaretti (2011) aponta que, da triangulação entre o método histórico, a atividade e a relação entre criança e sociedade, Elkonin evidenciou a origem histórica da brincadeira e suas fases no desenvolvimento individual, e denominou de jogo protagonizado a forma mais desenvolvida de brincadeira na idade pré-escolar.

\section{O Estudo das teses centrais de Elkonin sobre o jogo}

As teses centrais de Elkonin sobre o jogo são apresentadas na obra Psicologia do Jogo (Elkonin, 2009), na qual se baseia o presente trabalho. Versam sobre o desenvolvimento histórico e individual do jogo e substanciam-se em sínteses teóricas, estudos históricos e dados de pesquisa genético-experimental, o que dá à obra uma característica de antologia acerca da produção de conhecimento sobre o jogo na antiga URSS, reunindo as principais pesquisas realizadas entre as décadas de 40 e 70 do século XX.

O trabalho que realizamos no âmbito do estudo bibliográfico consistiu em destacar as teses apresentadas pelo autor identificando os elementos teóricos, empíricos e historiográficos que consubstanciam cada tese. A partir daí, construímos sínteses acerca de cada uma delas. O trabalho foi norteado pelo objetivo de encontrar elementos que subsidiassem a organização da educação da infância tendo o jogo como atividade-guia.

\section{Tese 1: O jogo protagonizado tem origem histórica}

A tese da origem histórica do jogo protagonizado é a mais importante da teoria de Elkonin. Nas palavras do autor:

(...) pode-se formular a tese mais importante para a teoria do Jogo Protagonizado: esse jogo nasce no decorrer do desenvolvimento histórico da sociedade como resultado da mudança de lugar da criança no sistema de relações sociais.
Por conseguinte, é de origem e natureza sociais. (Elkonin, 2009, p. 80)

Algumas pesquisas etnográficas, geográficas e antropológicas trouxeram informações sobre a vida das crianças, permitindo algumas considerações para tentar responder a duas indagações feitas pelo autor:

A primeira é: Existiu sempre o jogo protagonizado ou houve um período da vida da sociedade em que não se conheceu essa forma de jogo infantil? A segunda: A que mudanças na vida da sociedade e na situação da criança na sociedade se deve o nascimento do jogo protagonizado? (Elkonin, 2009, p. 49).

Não há um momento histórico único em que surge o jogo, pois entre os diferentes povos o jogo surge em épocas diferentes. Para Elkonin (2009), importa enfatizar que as sociedades primitivas não reuniam condições objetivas suficientes para o surgimento do jogo protagonizado, dado o nível incipiente do desenvolvimento das forças produtivas, portanto, também das ferramentas, o que implica que, nessas sociedades, os pais podiam inserir seus filhos nas atividades produtivas sem nenhum tipo de preparo especial.

Em níveis intermediários de complexidade dos instrumentos de trabalho, à medida que as ferramentas foram se tornando mais elaboradas e seu uso mais complexo, organizaram-se formas especiais para que as crianças aprendessem a utilização das ferramentas, como sua confecção em tamanho diminuído de modo que, com a manipulação de tais objetos, passassem também a dominar seu uso.

A divisão do trabalho e o aparecimento de elementos da indústria complicam as possibilidades de inserção da criança na produção, adiando a aprendizagem para a atividade produtiva em idades posteriores (Elkonin, 2009).

O jogo protagonizado surge com a nova posição social da criança: como não pode ser inserida na sociedade através de uma atividade diretamente útil, ela reconstitui, por meio do jogo, esferas da vida adulta que não Ihe estão diretamente acessíveis. Assim, o uso dos objetos, as relações sociais e suas regras, que eram aprendidos pela criança no interior da atividade produtiva, serão agora aprendidos no jogo protagonizado que acontece no coletivo de crianças.

A reconstituição das atividades adultas se dá por meio da utilização de objetos lúdicos, substitutos dos reais e de uma ação especial com eles: a ação lúdica. Para Elkonin (2009), se uma das raízes históricas da brincadeira infantil é o trabalho, a outra é a arte. Com a arte dramática a humanidade criou uma forma de representear esferas da vida social sem um fim diretamente útil. Assim, a técnica da arte dramática parece, historicamente, ter influenciado o desenvolvimento do jogo infantil tal como o conhecemos hoje.

No decorrer da história essa forma de brincar foi transmitida entre as gerações, transformando-se na atividade que melhor mediatiza a relação da criança com o mundo (Nascimento, Migueis, \& Araújo, 2010). 
Tese 2: 0 surgimento do jogo protagonizado na ontogenia não é espontâneo, mas devido à educação

Para Elkonin (2009), a origem e o desenvolvimento do jogo na ontogenia estão ligados à assimilação da atividade humana e das relações sociais pela criança. Há nesse processo a orientação permanente dos adultos. Reside nesse fato a tese de que o jogo é fruto da relação entre a criança e o adulto, mais precisamente, da influência educativa que os adultos exercem na relação com a criança.

A comunicação direta, atividade-guia do primeiro ano de vida, é sucedida pela manipulação dos objetos mediada pelo adulto. A manipulação é condição essencial para o desenvolvimento das ações, que terão papel fundamental no desenvolvimento do jogo protagonizado. Elkonin (2009) afirma que o desenvolvimento da brincadeira na ontogenia possui uma ligação genética com a formação das ações com os objetos na primeira infância. Afirma o autor:

Denominamos ações com os objetos os modos sociais de utilizá-los que se formaram ao longo da história e agregados a objetos determinados. Os autores dessas ações são os adultos. Nos objetos não se indicam diretamente os modos de emprego, os quais não podem se descobrir por si sós à criança durante a simples manipulação, sem ajuda nem direção dos adultos, sem um modelo de ação (Elkonin, 2009, p.216).

Os adultos, ao fazerem uso dos objetos, demonstram os modos sociais de uso destes, que logo serão utilizados com autonomia pela criança.

Paulatinamente, ampliam-se as ações assimiladas na atividade conjunta com os adultos, abrangendo cada vez mais objetos, e manifestam-se, na conduta da criança, ações que são reflexos das suas relações com os objetos e com as pessoas (Elkonin, 2009).

As ações aprendidas na atividade com os adultos tornam-se lúdicas quando a criança transfere o uso de um objeto aprendido em uma ação para outras ações. Por exemplo: a criança aprende a pentear o cabelo com pente e passa a pentear as bonecas, e em outros casos pode usar uma régua para pentear a boneca.

Entre os dois exemplos citados há diferenças psicológicas importantes. No primeiro caso o foco da ação está no pente, e a criança generaliza a ação aprendida com ele (pentear-se) para outra (pentear a boneca). No segundo caso o foco da ação é a boneca, e na falta de um pente (objeto verdadeiro), a criança utiliza outro objeto que possa substituí-lo (objeto substituto). Aqui a criança separa o objeto verdadeiro (pente) do esquema geral de atuação e generaliza sua função. Vemos, então, a condição em que surge o uso dos primeiros objetos substitutos: nas situações em que falta um objeto para complementar a ação com o objeto central da brincadeira.

A explicação da utilização dos objetos substitutos é de extrema importância para uma psicologia do jogo.
Considerado por outras vertentes teóricas como elemento central da brincadeira e fruto de uma imaginação altamente desenvolvida, o uso dos objetos substitutos aparece, nos estudos realizados por Elkonin e seus colegas, como elemento secundário no jogo, que surge diante da necessidade de complementar a ação lúdica.

Quando a ação torna-se lúdica, seu desenvolvimento ulterior depende da adoção do papel. O papel - ser professor, mãe, bombeiro - sintetiza um conjunto de ações e regras sociais de conduta. Chamamos a atenção para o fato de que até esse momento a criança ainda não desempenha papéis; ela apenas reproduz, de forma desarticulada, as ações adultas - por exemplo, dá de comer à boneca, interrompe a alimentação e começa a passear com ela, depois volta a dar de comer, em seguida a põe para dormir e troca sua roupa. Por vezes as crianças também se envolvem com outros brinquedos, executam outras ações e depois voltam a desenvolver ações que praticavam com o primeiro brinquedo.

Um acontecimento que prepara o surgimento do papel no jogo é assumir o nome de um adulto. Quando a criança diz "Eu sou a professora Rosa", ela começa a comparar suas ações com as da professora.

Paralelamente ao desenvolvimento dos primeiros elementos do papel, as ações lúdicas apresentam-se cada vez mais articuladas umas com as outras, reproduzindo a lógica das ações da vida. Segundo demonstrações experimentais, o papel "refaz radicalmente as significações das ações e objetos" (Elkonin, 2009, p. 251) com os quais a criança opera e parece ser inserido "como de fora, com brinquedos temáticos que sugerem o sentido humano das ações realizadas com eles" (Elkonin, 2009, p. 251).

Assim, o surgimento e desenvolvimento do papel dão unidade e coerência às ações que cada vez mais representam o sentido das relações entre as pessoas no interior das atividades humanas.

Destarte, desde sua origem o jogo está ligado à atenção educativa que os adultos dispensam às crianças quando ensinam as formas de utilizar os objetos e, de forma consciente ou não, as formas de relacionamento entre as pessoas.

\section{Tese 3: O papel é a unidade fundamental do jogo.}

Seguindo a tese de Marx, empregada por Vigotski (1995) no estudo das relações entre pensamento e linguagem, Elkonin (2009) julgou necessário encontrar a unidade de análise da brincadeira, ou seja, o elemento mínimo que guarda em si as características essenciais da brincadeira, através da análise de sua forma mais desenvolvida - aquela em que as crianças representam papéis, fazem emprego de objetos lúdicos e apresentam ações lúdicas de natureza sintética e abreviada.

A partir de suas observações, o autor destaca os seguintes aspectos constitutivos da brincadeira: os papéis assumidos pelas crianças, as ações lúdicas de caráter sintético e abreviado, o emprego lúdico dos objetos e as relações autênticas entre as crianças. 
Assim, pode-se afirmar que são justamente o papel e as ações dele decorrentes o que constitui a unidade fundamental e indivisível da evolução da forma de jogo. Nele estão representados a união indissolúvel, a motivação afetiva e o aspecto técnico-operacional da atividade (Elkonin, 2009, p.29).

Para Elkonin, o jogo das crianças pré-escolares consiste na interpretação de um papel assumido pela criança. e este papel é a unidade que contém todos os elementos do jogo. O estudo do desenvolvimento do jogo, para não perder de vista sua especificidade nem a unidade dos processos que ele envolve, deve basear-se no entendimento da gênese do papel.

Até por volta dos três anos ainda não é consciente para a criança a relação eu-papel. A consciência dessa relação alcança seu auge na idade pré-escolar, quando a criança começa a expressar o entendimento de que cada papel deve ser representado de uma forma.

A criança protestar contra o companheiro por não estar cumprindo o papel adequadamente - dizendo na brin- cadeira de escola "Não é assim que o professor faz" - é um sinal de que ela conhece as regras daquele papel, o que nos permite deduzir que o papel se destaca claramente do eu infantil. Uma implicação disso é que, no jogo protagonizado, a criança é consciente de que está representando um papel, e não é o papel.

Ao longo do desenvolvimento do jogo muda o conteúdo representado. Para as crianças mais novas o sentido da brincadeira é executar ações dos papéis; para as crianças de idade mediana é representar as relações pessoais do papel; já no final da idade pré-escolar, as crianças captam os traços mais típicos do papel e os interpretam (Elkonin, 2009).

Com base nos resultados de experimentos em que se solicitava a crianças de diferentes idades que brincassem de um mesmo tema, Elkonin (2009) sugere dois níveis fundamentais do desenvolvimento do jogo, com dois subníveis cada. Note-se que as etapas de desenvolvimento do jogo fundamentam-se no desenvolvimento do conteúdo do papel.

As fases do desenvolvimento do jogo propostas por Elkonin (2009) são:

\section{Primeiro Nível (3 - 5 anos)}

Conteúdo fundamental do jogo são as ações objetais de orientação social.

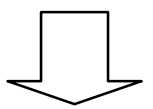

Subnível 1

- O conteúdo do jogo são ações como objetos dirigidos a companheiros do jogo

- Papéis são determinados pelo caráter das ações

- Ações monótonas

- Lógica das ações não reflete a lógica da vida

\section{Subnível 2}

- O conteúdo fundamental ainda é a ação com os objetos, mas está em primeiro plano a correspondência com as ações tal como ocorrem na vida real.

- Ampliação das ações.

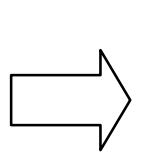

sũo as relações sociais entre as pessoas e o sentido social da atividade humana.



\section{Subnível 1}

- As ações do papel expressam o caráter das relações sociais

- Os papéis são bem delineados

- Maior variedade de ações.

- A lógica e o caráter das ações determinam-se pelo papel assumido

- Infração das ações é alvo de protestos

\section{Subnível 2}

- O conteúdo fundamental do jogo são as relações mais características do papel.

- A ordem das ações reconstitui a da vida.

- As regras de conduta do papel são claras.

- São enfatizadas ações com os diversos personagens do jogo

- A infração da lógica das ações é repelida com veemência.

Figura 1. fases do desenvolvimento individual do jogo segundo Elkonin. 
Frise-se que o desenvolvimento do papel no jogo está mais ligado à inserção da criança na realidade social do que à idade cronológica. A relação existente entre idade cronológica e desenvolvimento do jogo implica que, quanto mais velha é a criança, mais pode vir a conhecer.

Esse conhecimento dos níveis de desenvolvimento do jogo tem uma importância prática, pois possibilita identificar fases do desenvolvimento individual do jogo a partir da observação de como as crianças interpretam o papel.

\section{Tese 4: O conteúdo fundamental da brincadeira é o homem}

$\mathrm{Na}$ idade pré-escolar descortina-se para a criança o mundo das relações sociais. Assim, manifesta-se a necessidade de agir como o adulto; todavia, concretamente isso é impossível, então ela satisfaz essa necessidade na brincadeira, criando uma situação imaginária, interpretando papéis sociais, desempenhando as ações que os caracterizam e utilizando objetos substitutos.

Ainda que as crianças, principalmente as menores, sintam-se atraídas por determinados objetos ou brinquedos, o que de fato as motiva a brincar é o desejo de desempenhar um papel. Quando crianças se interessam por um estetoscópio, logo passam a executar com ele as ações como se fossem o médico.

Em uma série experimental conduzida por Slavinia (citada por Elkonin, 2009), a experimentadora retirava do jogo os brinquedos temáticos com os quais as crianças menores brincavam. Constatou então que, mesmo sem os brinquedos, elas não abandonavam o papel. A pesquisadora concluiu que o papel, embora com conteúdo incipiente, já existe no início da idade pré-escolar e que interpretá-lo faz a criança permanecer no jogo, mesmo que se retirem os objetos com os quais ela brinca. Por isso Elkonin afirma:

\footnotetext{
A base do jogo evoluído não é o uso do objeto, mas as relações entre as pessoas, mediante as suas ações com os objetos. Não é a relação homem-objeto, mas a relação homem-homem: a assimilação dessas relações transcorre mediante o papel de adulto assumido pela criança (Elkonin, 2009, p. 34)
}

Como são variadas as esferas da atividade humana e os tipos de relacionamento entre as pessoas, também são variados os temas e conteúdos das brincadeiras. Os temas do jogo são a reconstituição de aspectos da vida social, como brincar de casinha, médico ou escola, e demonstram o conhecimento da criança acerca da realidade social. O conteúdo é o aspecto característico central do jogo; ele reflete a inserção da criança na atividade humana e nas relações que se dão por meio dela, preenche e dá vida ao papel na brincadeira.

Assim, por meio da brincadeira a criança assimila a atividade humana e as formas de relacionamento entre as pessoas, sendo a forma acessível para que a criança se aproprie dos motivos e objetivos da atividade humana.

Tese 5: A transposição das significações, a abreviação e a síntese das ações lúdicas são as bases para a criança inserir-se nas relações sociais

A ação lúdica, conforme explica Elkonin (2009), é um tipo especial de ação cujo seu sentido é transmitido de forma sintética e abreviada. Vejamos um exemplo disso: crianças brincando de escola. A criança interpreta a professora passando a lição; para isso, basta que faça um gesto que sintetize a ação real da professora escrevendo a lição. Quando olha os cadernos, pode folhear um caderno imaginário, executando ações que transmitem a ideia da ação de folhear o caderno. O importante é transmitir para as outras crianças, que interpretam os alunos, o sentido da ação.

Se no jogo se reproduzissem todas as ações tal e qual a realidade, com todas as suas partes componentes, não haveria brincadeira, e sim, uma imitação mecânica e sem significado da realidade. Assim, atuar de forma sintética e abreviada é uma condição imprescindível.

Elkonin (2009) assinalou que existe e uma ação contraditória entre o papel e as ações ligadas a ele: quanto mais abreviadas e sintéticas são as ações lúdicas, maior é a profundidade da representação das relações sociais reproduzidas. Para compreender tal afirmação, recorremos ao desenvolvimento das ações lúdicas na brincadeira.

Para que a ação se torne sintética e abreviada é preciso que, antes, a criança realize a transposição de significados, com a utilização de objetos substitutos. Até os três anos, ainda é o objeto que determina as ações das crianças, pois a ação está plasmada no objeto.

A contradição fundamental da natureza das ações com os objetos é que, se por um lado as ações contêm o esquema geral de significação social do objeto, por outro apresentam as propriedades operacionais ligadas às características físicas dos mesmos (Elkonin, 2009). A ação com um pau em vez do cavalo ou com um pedaço de papel como se fosse um prato, ajuda a separar a ação do objeto com o qual esta ação está habitualmente ligada na vida real. Essa operação oferece a condição para a tomada de consciência da ação como tal.

A substituição de um objeto por outro se baseia na possibilidade de executar, com o objeto lúdico, a ação necessária para o desenvolvimento do papel. Graças a essa substituição, o aspecto técnico operacional da ação fica em segundo plano, tornando-a plástica e transmitindo unicamente seu significado geral (dar de comer, pôr para dormir, cuidar do doente, comprar e vender, passear, lavar-se).

Para Elkonin (2009), a abreviação e síntese das ações lúdicas são sinais de que a criança está assimilando o sentido humano das ações, por meio do realce das relações entre as pessoas que se dão nas atividades humanas. 
Tese 6: 0 jogo produz o desenvolvimento psíquico e da personalidade infantil

Uma vez que conhecemos a estrutura da atividade infantil, temos agora condições para compreender os nexos fundamentais entre jogo protagonizado e desenvolvimento infantil. A pergunta que fazemos é: o que acontece no jogo que permite o desenvolvimento de processos psíquicos e da personalidade infantil?

Segundo Elkonin (1987a), "Através do jogo o mundo das relações sociais, muito mais complexas que as acessíveis à criança em sua atividade não lúdica, é introduzido na sua vida e a eleva a um nível significativamente mais alto" (Elkonin, 1987a, p. 93, tradução nossa). Para o autor, esse elemento é um dos traços essenciais do jogo e nele está enraizada uma das significações mais importantes para o desenvolvimento infantil.

Como vimos, nos papéis representados pelas crianças estão contidas regras de conduta e de relacionamento social. Como no jogo o importante é representar bem o papel, a criança controla seu comportamento conforme normas de conduta. A criança percebe traços específicos das condutas, individualiza-os no papel e, quando os generaliza, assimila uma forma de ser: médico, professor, ladrão, policial, dentre outros papéis disponíveis na rede de relações sociais.

Ao assumir um papel, a criança ao mesmo tempo é ela mesma e outro. Para Elkonin (1987a), é difícil para a criança observar seu próprio comportamento, mas no jogo ocorre um desdobramento entre o "eu real" e o "eu imaginário" e torna-se visível para a criança um conjunto de ações de um papel. Segundo Elkonin (2009), "A criança controla com dificuldades suas próprias ações; mas, as controla de maneira relativamente mais fácil, por dizer assim, postas exteriormente e dadas sob a forma de ações de outra pessoa." (Elkonin, 1987a, p.99, tradução nossa).

A conduta da criança é reestruturada na brincadeira, tornando-se arbitrada, isto é, controlada por regras de um determinado modelo de conduta (Elkonin, 2009).

Existe, dessa forma, um movimento de reflexão em que a criança compara seu comportamento na brincadeira com um modelo. Essa reflexão é ainda muito incipiente, mas o importante é que essa função nasce na brincadeira (Elkonin, 2009).

Nesse movimento de assumir papéis, atuar conforme normas de conduta e sistemas de relacionamento social, ser ao mesmo tempo eu e outro e comparar-se com um modelo, a criança vai assimilando as normas de relacionamento social e organizando sua própria conduta.

A adoção do papel também oferece a condição necessária para que a criança opere sob novas perspectivas, uma vez que a criança ocupa uma nova posição em uma relação, favorecendo o processo de descentramento cognitivo. Também a alteração dos significados dos objetos desempenha papel central nesse descentramento, pois exige a criação de novas formas de agir com os objetos (Elkonin, 2009).

Há elementos que indicam o jogo como fase de transição para etapas mais desenvolvidas do pensamento. afirma Elkonin:
Se nas etapas iniciais se requer um objeto substitutivo e uma ação relativamente desenvolvida com ele (etapa da ação materializada, segundo Galperin), nas etapas posteriores do desenvolvimento do jogo, o objeto já se manifesta como signo da coisa mediante a palavra que o domina, e a ação com gestos abreviados e sintetizados concomitantemente com a fala. Assim, as ações lúdicas apresentam um caráter intermediário e vão adquirindo paulatinamente o de atos mentais com significações de objetos que se realizam no plano da fala em voz alta e ainda se apóiam em ações externas que, não obstante, já adquiriram o caráter de gestoindicação sintético (Elkonin, 2009, p. 415).

Assim, podemos dizer que o jogo "afeta os aspectos mais importantes do desenvolvimento psíquico da personalidade do pequeno em conjunto, o desenvolvimento de sua consciência" (Elkonin, 1987a, p. 84, tradução nossa).

\section{A teoria do jogo de Elkonin e a Educação Infantil}

No campo da Psicologia, a teoria de Elkonin estabelece-se como uma original e genuína Teoria Histórico-Cultural do Jogo. Ao explicar as fases do desenvolvimento individual e evidenciar o papel do adulto, permite estabelecer pressupostos para a organização dessa atividade na Educação Infantil. Desfaz-se a ideia de que o jogo infantil é fruto de impulsos internos ou da tentativa de fugir das imposições do mundo adulto; sua origem está nas relações sociais da criança e é atividade que a insere na sociedade promovendo sua humanização, tal como vimos no item acima.

Nessa perspectiva, o papel da escola de Educação Infantil é proporcionar condições para que essa atividade seja rica e diversificada. Como é possível enriquecer o jogo protagonizado? Se seu desenvolvimento relaciona-se com o conhecimento que a criança tem da realidade, quanto mais criar condições para que a criança conheça seu entorno, mais a escola proporcionará seu enriquecimento.

Dessa forma, parece correto afirmar que o desafio proposto à Educação Infantil, que tem como pressuposto o jogo como atividade-guia da criança, é ampliar o conhecimento da criança acerca das relações sociais e da atividade humana, para que esses conhecimentos transformem-se em matéria prima para o jogo infantil.

O objetivo a ser alcançado em relação ao desenvolvimento do jogo protagonizado é possibilitar às crianças, ao final da idade pré-escolar, representarem os papéis interpretando suas relações sociais mais típicas.

Retomando-se a discussão realizada por Elkonin (1987b) sobre a periodização, constata-se que o jogo protagonizado corresponde ao grupo de atividades do sistema criança-adulto social, no qual a orientação predominante é a assimilação de objetivos, motivos e normas das relações entre as pessoas. Assim, é preciso ter claro: o que está em 
primeiro plano nessa atividade é a reprodução das relações sociais entre as pessoas através da interpretação dos papéis.

Partindo dessa proposição, discutiremos dois entendimentos sobre o jogo na Educação Infantil que se afastam das ideias defendidas por Elkonin: a utilização do jogo como instrumento didático e o jogo como mera recreação.

A utilização do jogo protagonizado como instrumento didático não possibilita o desenvolvimento do papel. Para Elkonin (2009), a importância didática do jogo é extremamente limitada, pois os elementos fundamentais da atividade-guia infantil ficam relegados a segundo plano. Afirmam Kravtsov e Kravtsova (2010)

Na classificação do brincar há até mesmo um tipo de brincadeira especial - a brincadeira didática. Esta é uma brincadeira educativa. Mas na pesquisa das características da brincadeira didática, V. V. Davydov mostrou que, em um caso, a brincadeira perde suas características essenciais e, em outro caso, ela perde o sentido didático (Kravtsov \& Kravtsova, 2010, p. 24, tradução nossa).

A importância didática do jogo é limitada porque não se aprende sobre as propriedades dos objetos ou noções científicas no jogo protagonizado: tais aprendizagens se dão em atividades dirigidas para esse fim. Quando se transforma o jogo em uma atividade para ensinar um conceito, sua especificidade está sendo relegada a segundo plano, portanto ele está sendo descaracterizado, transformando-se em outra atividade.

Essa ideia de utilizar o jogo como instrumento didático não é nova e sustenta-se na análise psicológica de que a motivação para o jogo - atividade que a criança realiza porque a natureza infantil é dada à não seriedade característica do jogo - é o prazer (Brougère, 1995). Por isso, propõe-se utilizar o jogo como recurso de ensino - um meio de seduzir a criança para aprender conteúdos sérios.

Por outro lado, pensar o jogo protagonizado como recreação tampouco corresponde a uma organização pedagógica que possibilite o desenvolvimento do papel. Essa forma de compreender o jogo parte da ideia de que o jogo tem conteúdo fútil. Ainda assim, é necessário na Educação Infantil, para que as crianças descansem e retomem o fôlego para o trabalho com os conteúdos verdadeiramente sérios.

Uma vez compreendida sua importância para o desenvolvimento infantil, como vimos no item anterior, não faz sentido contrapor o jogo a outras atividades na Educação Infantil. Mesmo assim, não se trata de defender que seja a atividade preponderante ou que a criança apenas se interesse pelo jogo na idade pré-escolar.

O jogo proporciona o desenvolvimento das mais importantes transformações do período, mas é incorreto "universalizar a importância do jogo para o desenvolvimento psíquico" (Elkonin, 2009, p. 399). As atividades criativas e de expressão, o conhecimento de fenômenos da natureza, situações envolvendo a sociedade deste e de outros tempos e pessoas deste e de outros lugares, a apreciação estética, assim como a convivência com a cultura escrita que forma nas crianças uma atitude leitora e produtora de textos, têm grande importância para o desenvolvimento infantil e não devem perder espaço para o jogo protagonizado. Na verdade, tais atividades enriquecem também a atividade-guia, pois criam condições para que as crianças conheçam mais sobre o mundo.

Para essa discussão, é conveniente retomar Leontiev (2010) quando afirma que a atividade-guia não é aquela que a criança faz a maior parte do tempo, mas aquela que, por seu conteúdo e estrutura, possibilita o desenvolvimento de processos psicológicos essenciais ao processo de humanização que acontece na pequena infância.

Assim, trata-se de criar condições para que essa atividade possa se desenvolver com qualidade. A organização e o uso dos ambientes na escola infantil e a gestão do tempo aí vivido pelas crianças constituem parte dessas condições fundamentais. Por isso é essencial um um tempo livre diário que as crianças possam gerir de forma autônoma, escolhendo como atividade o jogo protagonizado.

Da mesma forma, intervenções do professor são fundamentais para o desenvolvimento do papel. A apresentação dos objetos (com o que se brinca), o cenário (onde se brinca), as ações e relações interpretadas na brincadeira (como se brinca) devem ser alvo da atenção dos educadores que lidam com as crianças pequenas.

Elkonin (1987a) destaca que os brinquedos devem ser os necessários e os mais simples possíveis. Ressalta que nos níveis iniciais do desenvolvimento do jogo são necessários mais brinquedos temáticos, pois estes ajudam a criança a adotar o papel; porém esses brinquedos devem ser gradualmente retirados pelo professor. $\mathrm{O}$ intuito dessa ação é auxiliar que a adoção de papéis passe a se estabelecer a partir do conhecimento das regras internas do papel, que não fique dependente dos objetos imediatamente disponíveis. Nesse sentido, a apresentação das ações e relações dos papéis sociais é fundamental.

Um elemento a observar é que, da mesma forma que brinquedos temáticos, o cenário onde se brinca também tem o poder de sugerir temas. Deixar a sugestão a cargo do cenário pode tornar a brincadeira monotemática, daí a necessidade da intervenção do professor, sugerindo, ou mesmo discutindo com o grupo de crianças temas possíveis para a brincadeira antes que esta se inicie. A Teoria Histórico-Cultural do Jogo sugere que as crianças possam interpretar papéis ligados a uma variedade de temas, pois temas diferentes exigem a criação de situações imaginárias distintas e, por vezes, mais complexas. Da mesma forma, é fundamental que as crianças possam interpretar uma ampla gama de papéis. Frise-se que o papel contém os valores da sociedade atual, impregnada de preconceitos, portanto a intervenção do professor precisa auxiliar a criança na reflexão crítica sobre esses valores (Duarte, 2006).

O desenvolvimento infantil depende de mediações de qualidade. É adequado supor, seguindo a Psicologia Histórico-Cultural, que, à medida que se criam as condições para o desenvolvimento do jogo, possibilita-se que os processos psíquicos e da personalidade se reorganizem e tomem for- 
mas qualitativamente superiores. Pensando-se a Educação Infantil como espaço e tempo dedicados ao desenvolvimento da criança, esse nível da educação precisa comprometer-se com as condições em que as crianças brincam.

\section{Considerações finais}

Com o estudo das teses centrais da Teoria Histórico-Cultural do Jogo de Elkonin foi possível identificar os elementos centrais da atividade-guia da criança em idade pré-escolar e seu papel no desenvolvimento, bem como destacar o lugar ocupado pelo jogo na organização das atividades na escola de Educação Infantil. Isso possibilitou apontar formas de intervenção do professor na criação das condições adequadas para a constituição deste jogo protagonizado, tais como sugestão de temas, a discussão dos conteúdos, a adequação dos materiais e dos espaços; entretanto, estudos empíricos devem ser realizados com intuito de verificar as melhores formas dessa intervenção pedagógica, com objetivo de melhor possibilitar o desenvolvimento do papel, unidade fundamental do jogo.

\section{Referências bibliográficas}

Brougère, G. (1995). Jogo e educação. Porto Alegre: Artes Médicas.

Duarte, N. (2006). Vamos brincar de alienação?. Em A. Arce \& N. Duarte (Org.), Brincadeira de papéis sociais na Educação Infantil: as contribuições de Vigotski, Leontiev e Elkonin (pp.111-138). São Paulo: Xamã

Elkonin, D. (1987a). Problemas psicológicos del juego en la edad escolar. Em M. Shuare (Org.), La psicologia evolutiva e pedagógica en la URSS - Antologia (pp.83-102). Moscou: Progresso.
Elkonin, D. (1987b). Sobre el problema de la periodização do desenvolvimento psiquico na infancia. . Em M. Shuare (Org.), La psicologia evolutiva e pedagógica en la URSS - Antologia (pp. 104-124). Moscou: Progresso.

Elkonin, D.(2009). Psicologia do jogo. São Paulo: Martins Fontes.

Facci, M. G. D. (2004). A periodização do desenvolvimento psicológico individual na perspectiva de Leontiev, Elkonin e Vigotski. Cadernos CEDES, 24(62), 64-81.

Kravtsova, E. E., Kravtsov, G. G. (2010). E. Play in L.S. Vygotsky's Nonclassical Psychology. Journal of Russian and Este European Psychology, 48(4), 25-41.

Lazaretti, L. R. (2011). A compreensão histórico-cultural da brincadeira infantil: das hipóteses de Vigotski às elaborações de Elkonin. Em Anais eletrônico do V Encontro Brasileiro de Educação Marxismo: Marxismo, Educação e Emancipação Humana. Florianópolis, SC. Recuperado: 16 mai 2012. Disponível: http://www.5ebem.ufsc.br/ trabalhos/eixo_04/e04c_t002.pdf

Leontiev, A. N. (2010). Uma contribuição à teoria da psique infantil. Em L. S. Vigotski, A. R. Luria \& A. N. Leontiev, Linguagem, desenvolvimento, aprendizagem (pp.59-83). São Paulo: Ícone.

Nascimento, C. P., Araújo, E. S., \& Migueis, M. R. (2010) O conteúdo e a estrutura do jogo na educação infantil: o papel do jogo. Em A. J. Rigon \& C. P. Nascimento (Org.), A atividade pedagógica na teoria histórico-cultural (pp.111-119). Brasília: Liber Livro, 2010.

Vigotski, L. S. (1995). Obras Escogidas (Vol. II). Madrid: Visor.
Recebido em: 27/07/2012

Reformulado em: 25/02/2013

Aprovado em: 05/04/2013

\section{Sobre as Autoras:}

Suzana Marcolino (suzanamarcolino@yahoo.com.br)

Programa de Pós-Graduação em Educação, Unesp/Marília, bolsista CAPES

Flávia Cristina Oliveira Murbach de Barros

Programa de Pós-Graduação em Educação, Unesp/Marília, bolsista CAPES.

\section{Suely Amaral Mello}

Professora doutora do Programa de Pós-Graduação em Educação, Unesp/Marília.

Agradecimento à Maria de Fátima de Andrade pelo auxílio na correção e formatação do artigo. Agradecimento à CAPES pelo apoio à pesquisa. 